\title{
United We Stand: seeking cohesive action in early childhood education and care
}

\author{
KYM MACFARLANE \& PATRICIA LEWIS \\ School of Human Services, Griffith University, Meadowbrook, Queensland, Australia
}

\begin{abstract}
Early childhood education and care (ECEC) is a complex field comprised of practitioners who possess disparate qualifications and understandings. While this diversity provides richness in terms of practice possibilities, it can also be challenging in terms of the divisions produced by different disciplinary and philosophical approaches. This is particularly evident in relation to how different practitioners advocate for who holds the truth within their grasp, in relation to best practice within this field. Such advocacy can ultimately divide practitioners in ways that are particularly problematic when political activism is necessary. This article examines the implications of the workforce divisions within ECEC in Queensland, Australia and the impact of such divisions on how practitioners advocate in particular contexts. The authors argue that differences that exist in disciplinary approaches have tended to highlight concomitant differences in understanding about what are regarded as being exemplary practices and in the quest for 'best practice'. This means that in times when political activism or advocacy is required, ECEC practitioners are divided rather than united as to what high-

quality/exemplary practices might actually look like. Such division has constrained rather than enabled practitioners in terms of how they support each other in the practice and political arenas in Queensland and in Australia as a whole. It is suggested that it might be better to gain advantage from a more united approach. The authors use the work of Pierre Bourdieu, who situates social and systemic practices as 'games' of practice; and that of Michel Foucault, who conceptualises such notions as 'games of truth and error'.
\end{abstract}

\section{Introduction}

The field of early childhood education and care (ECEC) in Australia has always been a complex one. This complexity is compounded by the fact that each state and territory has its own regulations and approaches regarding how the field is comprised and also how certain practices are enacted. Thus, when engaging practitioners [1] from ECEC in any discussion or debate, succinctly united approaches to particular issues and problems cannot be expected.

While such a notion can be enriching at times, it can also prove problematic, especially in contexts where practice is hierarchical, and also when political advocacy for the sector as a whole is needed. Moreover, some states in Australia, such as Queensland and Western Australia, have regulations that strongly differentiate practice by privileging 'traditional' professions over those that are more practically based (Burton \& Lyons, 2000), making unified engagement more difficult than usual.

This article explores such a problem of fragmentation in relation to the ECEC field in Australia, using the state of Queensland as an example of Australian ECEC practice. To do so, the authors use the conceptual framework of Pierre Bourdieu (1984, 2001), which situates social and systemic practices, such as those that occur in ECEC, as constituting a field of practice. In Bourdieu's $(1984,2001)$ terms, practitioners in ECEC participate on this field like 'players in a game' (Macfarlane, 2006). The authors also use the work of Michel Foucault $(1979,1980,1984)$ 
relating to discourse and regimes of truth, as a means of situating the ECEC field as problematic. The article therefore considers and explores contemporary social and systemic practice in the ECEC field, deconstructing these practices as 'games of truth and error' (Foucault, 1985, p. 6).

\section{Understanding the Queensland Game}

In Australia, the ECEC sector is quite diverse. ECEC policy in this country is implemented at a federal level and, as well, each state of Australia has its own regulations regarding ECEC. This means that in some states, such as New South Wales, workforce differences between differently qualified professionals might not be as obvious as those in other states. Therefore, in order to draw some comparisons between practitioner ideologies, it is important to choose a state where the issues are the most problematic and contradictory. Although each state in Australia might seek to claim this dubious honour for a variety of reasons, it is in Queensland that the differences between care and education are most stark. As Macfarlane and Lewis (2004, p. 57) state, in Australia, 'it is the states with the most extreme industrial conditions that bear examination, as it is these conditions that create the impetus for possible changes to occur'. Thus, an examination of Queensland's ECEC workforce regulations and policy will provide a useful lens for determining what issues in Australia are most problematic.

In recent years the ECEC field in Queensland has negotiated significant ECEC policy change (Department of Communities, Disability Services and Seniors [Queensland], 2006; Queensland Government, 2008). In fact, it is in Queensland that some of the divisions between 'care' practitioners/professionals (those with non-education qualifications obtained at training institutions or universities) and professionals (those with traditional education qualifications obtained at universities) in ECEC have been most strongly highlighted. As early as 1988, Petrie explored the notion of the care and education dichotomy that was dividing the ECEC sector, arguing for a more streamlined approach to practice, which situated education and care more equitably. In the years since this article was written, it is arguable that this dichotomy is alive and well, particularly in Queensland (Macfarlane \& Lewis. 2004). As Macfarlane and Lewis (2004, p. 59) state in their historical analysis of child care in Queensland, 'teachers in child care, in fact all child care workers, struggle to be recognised as professional to a greater degree than their counterparts in other early childhood sectors' (Burton \& Lyons 2000). It is the situation of child care as 'care only' in this state (Burton \& Lyons, 2000) that works to produce an inequitable 'game' on the Queensland ECEC field.

Moreover, Elliott (2006) highlights this policy and practice fragmentation by stating that, while in the 1980s policy frameworks were designed to minimise the differences between care and education in early childhood services, more recently funding shifts, have widened the care/ education dichotomy. Elliott (2006, p. 11) states:

The funding shift from 'education' to 'care' without also providing strong developmental and

learning programs in child care centres has widened the care-education divide and disadvantaged

countless children. That child care centres provide the only early childhood service in some

communities passes almost unnoticed.

While current Queensland ECEC policy has endeavoured to address this very issue highlighted by Elliot, recent announcements by the Premier of Queensland, the Honourable Anna Bligh, have ironically situated this policy as exacerbating rather than eliminating this dichotomy. While most ECEC practitioners would undoubtedly welcome the recent state and federal government attention that has been paid to the importance of the early years in policy formulation, governments are still designing policy in line with the care and education dichotomy. The new Queensland policy direction separates care and education for $0-5$ year olds by establishing more educational sites for 3-4-year-olds in the form of 240 more kindergartens across the state. In the same policy release, (Queensland Government, 2008), the Premier announced that younger children will be given access to 'better' early years' services by the Queensland government joining with the federal government to give support to child care centres to provide 'better' early childhood education, particularly for 3-4-year-old children.

The use of the term 'better' has significance here, as it infers that what has previously occurred for 3-4-year-olds prior to this policy was not high quality or that quality was in no way 
evident. As Foucault (1991, p. 46) attests, such rhetoric is 'dangerous' as it produces flawed understandings that can limit and narrow perspectives. In this case, this policy rhetoric ironically strengthens the notion that ECEC practice for 3-4-year-olds in child care contexts is not 'as good as' or 'does not represent' early childhood education. While the intention of such policy may be quite genuine, in terms of improving educational quality for 3-4-year-olds, such policy, by assumption and omission (Bowe \& Ball, with Gold, 1992), also accentuates the impression that child care is exclusive of education - a position the ECEC sector neither supports nor accepts.

In Foucault's (1980) terms, such policy rhetoric both enables and constrains both policy and practice. For Foucault, our common-sense 'reality' is constituted in language, or, more precisely, in patterns of language use (Macfarlane, 2006). To take Foucault's view is to understand that particular patterns of language use can work to produce understanding of what is 'reasonable' or 'true'. An analysis of the above-mentioned policy rhetoric suggests that the most recent Queensland government investment in ECEC produces a difference between those children who are 'entitled to education' and those who are 'entitled to care'. For example, the government's own figures state that of the 53,000 3-4-year-old children in Queensland, only 12,000 attend an early childhood centre where a qualified teacher delivers 'a recognised education program'. Of the 29,000 who attend child care centres, only $10 \%$ have access to 'an education program delivered by a qualified teacher' (Queensland Government, 2008). The Queensland government's solution to this issue is to spend 300 million dollars building new 'extended' kindergartens for 3-4-year-olds and an as-yet-unannounced sum on providing 'support' to the child care centres currently 'offering a valuable service' for working families. Thus, in the Premier's terms, child care centres provide a 'service', while kindergartens provide 'better' early childhood education and care (Queensland Government, 2008). The use of such rhetoric implies that 'teachers' who work in kindergartens provide education and care while 'teachers' and 'workers' in child care provide a service, possibly care, but no education.

Such a position does little to build the morale of those who are currently employed in the child care sector. These employees have been part of a sector that has been suffering from underresourcing and a lack of support for many years. It is well documented that staff in such centres are consistently subjected to public criticism about their training and also to conjecture about their practice (Macfarlane \& Cartmel, 2007). This conjecture has even intensified recently to the point where child care for infants and toddlers has been referred to as child abuse (ABC.net.au, 2008).

There would be few in the ECEC sector who would not argue that attention to the education of 3-4-year-olds is crucial for those children and their families at such a critical stage of life. However, a further argument could be that the 300 million dollars could have been better spent improving the position of the child care sector so that the education of children aged 0-5 years could be improved - but it is unlikely that such a move is 'thinkable' in the current climate of ECEC in Queensland. The reality in the ECEC sector in Queensland is that the discursive organisation of the field (Foucault, 1980) - that is, the way in which the players on the field understand proper ECEC practice - does not allow for child care to be thought of as education at a policy level. Child care is produced as just that - 'care' - and, as such, the only way it can be considered to be education is to add education to its remit and call it by another name. Child care discourse (Moss, 2006) produces such care largely in terms of health practice and not educational practice, particularly when it relates to children from birth to three years of age. Therefore, while the ECEC sector gives credence to the fact that practice with children from birth to age three involves understanding children's development and learning (Hutchins \& Sims 1999; Macfarlane \& Cartmel, 2008), many within and outside the sector do not consider this attempt to provide early learning in child care to be as 'good as' education in programs provided by qualified (i.e. four-year-degree) teachers.

\section{And If That Isn't Enough}

This workforce fragmentation is currently present alongside shifting policy positions in ECEC, which are not only privileging education over care but are also privileging notions of integrated or inter-professional practice in the early years. These changes have been highlighted and sometimes supported by academics in the field in publication work and research efforts (Farrell et al, 2004; 
Macfarlane \& Lewis, 2004). Additionally, such changes have been mirrored in government policies nationally in the National Agenda for Early Childhood (2003) (Department of Families, Housing, Communities and Indigenous Affairs [FaHCSIA], 2004b) and in the concomitant Stronger Families and Communities Strategy (SFCS; 2004-2009) (Department of Families, Housing, Communities and Indigenous Affairs [FaHCSIA], 2004a), as well as state-wide in the Towards an Early Years Strategy (EYS) (2006) (Department of Communities, Disability Services and Seniors [Queensland], 2006) and, most recently, in the federal government's Family Support Program (Department of Families, Housing, Community Services and Indigenous Affairs [FaHCSIA], 2009). Additionally, the Council of Australian Governments (CoAG) (2009) policy document entitled 'Investing in the Early Years - A National Early Childhood Development Strategy' has a much more specific approach to the notion of integrated/inter-professional practice.

These policy directions are reasonably new additions to the sector and have been introduced to promote a new focus on the early years, covering loosely the birth-to-eight-years-old age group. Such policy change has been underpinned by recent government approaches to producing local environments that engender practices to support children and families and to targeting the notion of 'healthy' families, thereby addressing certain social and systemic problems and disadvantages within communities as early as possible. These recent changes in policy direction have largely followed work in the UK around the notion of integrated/inter-professional practice (SureStart, 2008). Such work has been underpinned by literature producing the Sure Start program (David et al, 2003) and by the work of academics such as Moss (2002, 2006), Moss and Petrie (2002), and Moss and Pence (1994). The above-mentioned policy changes in Australia have mirrored these UK directions (particularly in the work undertaken in the SFCS around the Communities for Children $[\mathrm{CfC}]$ project). While such policy moves are welcome additions in terms of lessening the fragmentation in the sector, they are occurring alongside powerful discursive frameworks that produce and govern child care practice. Thus, as Moss (2006) attests, such moves are highlighting differences rather than reducing fragmentation, and they make evident the obstacles to a more united approach that countries like New Zealand, for example, enjoy.

To borrow from Bourdieu, then, it is necessary to examine ways in which social and systemic practice relating to practice in the ECEC field are constituted and understood. The work of Bourdieu $(1984,2001)$ is used here as a means of understanding how particular dispositions of individuals are produced and govern the way in which these individuals engage in social and systemic practices such as ECEC. Additionally, this understanding will be used to inform how these dispositions work to produce practice by professionals in the ECEC field in Queensland and in Australia as a whole. Thus, aspects of this practice will be examined to develop an understanding of how such practice is discursively produced (Foucault, 1980) in contemporary contexts, and how this discursive production contributes to the habitus (Bourdieu, 1984, 2001) of individuals, leading them to adopt particular dispositions and understandings as 'truth' (Foucault, 1978, 1980, 1984).

\section{Deconstructing the Field in Queensland}

\section{Revisiting History}

The inequitable game that exists in Queensland has been historically constituted and embedded in policy as a result of many somewhat unrelated but important historical events. One such event occurred in 1996, when the Queensland Industrial Relations Commission (QIRC) handed down a landmark decision that was to have a significant impact on the childcare field in Queensland (Macfarlane \& Lewis, 2004). A claim that early childhood teachers working in day care should receive pay parity with teachers in other sectors went before the Commission. During these hearings this claim was reduced to one issue - namely, whether teachers employed in day-care centres were actually teaching (Macfarlane $\&$ Lewis, 2004). The decision was that teachers in day care were not teaching - they were merely providing a developmental program. It was decided that, as a developmental program required 'less' skill, these teachers did not deserve pay parity (Burton \& Lyons, 2000). The Industrial Court endorsed a discursive shift that acted to privilege education over development. As it is an organisation accorded the status of defining 'truth' in this community, its decision in turn reflected a particular position that demarcated the difference between education and development (Macfarlane \& Lewis, 2004). In this instance, the lines 
between education and development were not blurred. Education was clearly more worthwhile, and those who provided education were worth more fiscally. Thus, the position of all childcare practitioners, particularly those who were teachers, was diminished (Macfarlane \& Lewis, 2004).

During the Industrial Court case, private long day care providers argued against the pay claim (Burton \& Lyons, 2000). Employers' arguments centred on the fact that a qualified teacher who was not required to provide an educational program was moreover not entitled to remuneration for such a program. Significantly, one employers' organisation argued:

If Teachers [sic] are to have a significant place in childcare it needs to be on the basis that they are doing something conceptually and identifiably different to other childcare workers. If this is not the case and the view is maintained that they do the same thing as other workers only a whole lot better, then the simple reality is that the childcare industry does not, in most cases, want or need what they have to offer. (Local Government Association final submission, QIRC, 1996,

p. 11, in Burton \& Lyons, 2000)

This particular industrial position that is still part of law in Queensland endorsed the divide between care and education, making it very difficult for care to be considered as significant as education. This industrial position has had an impact on all involved in ECEC in this state, as other policy and industrial decisions that have followed it have continued to endorse the notion that education matters more than care. This endorsement has also led to the notion that education is conducted in more formalised environments and that informal environments represent care and so cannot include education. This position produces divisions between those ECEC practitioners in child care and those in education settings and also means that the role of the 'players' in this inequitable game is considerably more complex.

\section{Impacting the Players}

The most important individuals participating/engaging in the game on the ECEC field are the players. Without the players there is no game, and thus these individuals have a key role in determining how successfully policy direction in ECEC is implemented. However, it is at present the players - young children, their families, staff, prospective practitioners (students), academics and some lobby groups - who are most at risk.

The above-mentioned players are categorised and governed (Foucault, 1980) in particular ways and perform on the field of ECEC in different environments. To begin with, children and families engage in the ECEC game via participation in child care centres, community organisations, government programs (sometimes created by particular policy initiatives), community kindergartens and school-aged care programs, and via health initiatives. ECEC staff exist in various roles as directors, group leaders, assistants (usually in child care centres), teachers (in child care centres, schools and kindergartens), health workers (in government, schools and community organisations), community workers (in neighbourhood centres and community organisations), paediatricians and other medical staff. Students engage in preparing for practice in the ECEC sector at university, TAFE (technical and further education) and other training organisations, both government-run and private. Academics and trainers from various disciplines engage with students in their preparation, and work within their disciplinary frameworks to produce notions of 'proper' practice in early childhood. Finally, lobby groups unite in terms of their own understandings of propriety (Rose, 2000; Macfarlane, 2006) and truth (Foucault, 1980) about early childhood practice, and thus develop agendas that are underpinned by this knowledge and position. Such players are indeed accorded different status (Foucault, 1980) and have different opportunities to speak authoritatively (Ball, 1990).

The information above does not constitute an exhaustive list but it is at least diverse and thus points to the fact that the road to integrated practice - that is, to practice that acknowledges and applies interdisciplinary knowledge bases - is a complex one. In Bourdieu's $(1984,2001)$ terms, it is the habitus of the aforementioned players that will undoubtedly add to such complexity. According to Bourdieu, an individual's habitus consists of 'dispositions, schemas, forms of know-how and competence, all of which function below the threshold of consciousness' (Macfarlane, 2006). Consequently, individuals develop particular beliefs and understandings that anchor and produce thinking and practice in particular ways. This means that players in the game 'unconsciously' 
adhere to the 'rules', which are produced by how the game and field are discursively organised (Macfarlane, 2006). Following Bourdieu, then, the training and preparation undertaken by each of the individuals in the game work to add to or produce their habitus, thereby determining how they will interpret the rules of the game. Moreover, Foucault also contributes to such a notion in terms of his identification of the development of 'regimes of truth' (1980, p. 131). According to Foucault (1980), individuals are produced as subjects and, in this case, players, in terms of how they understand and internalise particular regimes of truth about propriety. Thus, certain players are likely to believe that they 'hold the truth within their grasp' about practice, and it is this truth that will govern how they perform on the field. The multiplicity of players in the game on the ECEC field indicates that, at best, understandings of truth about practice in ECEC will be substantially diverse. While this diversity might enrich the practice and knowledge that will contribute to work undertaken with young children and their families, it can also prove problematic in terms of progress towards lessening fragmentation. The questions to ask concern which aspects of truth about practice will be privileged (Foucault, 1980), and which particular practitioners will eventually be accorded the right to speak (Ball, 1990).

In terms of the players in the game on the ECEC field, many have been participating in the game for a long time; however, some are only just beginning to realise that they are actually on the field. The moves to integrated practice are changing the landscape of the field to include a greater variety of players - for example, health professionals, allied health professionals and social workers. Such a notion, again, is likely to be enriching, but it is also possibly confronting, particularly if players have not previously privileged knowledge of early childhood education, care and development within their practice frameworks. This means that both their habitus and their perceptions of propriety might well be infringed upon.

An example of such an integrated or inter-professional context is evident in the Communities for Children (CfC) project currently being enacted nationally. This particular project has its logic and underpinnings in the discipline of community development and capacity building. However, FaHCSIA, the Commonwealth government department responsible for overseeing this project, has included in the program brief a highly intense focus on early childhood, particularly on the theory, literature and knowledge underpinning the development and learning of children from birth to five years old. This means that some of the individuals responsible for overseeing particular CfC projects across the country have never before specifically incorporated such knowledge into their practice. These individuals are now, however, looking to incorporate a whole new body of knowledge about ECEC practice into their own practices, which are already produced by their own particular regimes of truth about 'proper' practices and 'proper' knowledge (Macfarlane, 2006). Thus, the possibility of increased complexity exists, along with the difficulties of aligning multiple approaches to practice. Additionally, new players are being introduced into the game and new referees are now part of the ECEC field.

Clearly, the above-mentioned additions to the game represent new and exciting opportunities for this field. However, while the ECEC field is impacted upon by several competing discourses produced by competing regimes of truth, the position of the players is increasingly problematic. Moss (2006) represents such a position in terms of the moves to integrated practice in the UK. Moss states that competition between pedagogic discourses and child care discourses is making the moves to integrated practice in this country extremely difficult. This position of competing practice discourses is replicated and intensified in Australia, where reforms are moving quickly and where the care/education dichotomy is growing and not shrinking (Elliott, 2006), in relation to such reforms. What is most apparent is that, unless the complexities that some of these policy initiatives create are fully understood and accommodated, it is likely that new and exciting opportunities will only be achieved for a few. It is also likely that the players in the game - including children and families - will be the most confused (Elliott, 2006), because the rules of the game are changing too quickly.

Therefore, for a field already complicated by a care/education dichotomy that is alive and well, moves to integrated practice pose a significant issue for the players in this particular game. As the ECEC field is being impacted upon by players both old and new, the knowledge base of early childhood is being eroded by its own fragmentation. The ECEC sector has a history of turmoil, but its knowledge base is underpinned by multiple theoretical approaches that view children holistically, as active and independent learners who learn best when they are actively involved in 
negotiating their own learning and exploring their own interests (Hutchins \& Sims, 1999; Grieshaber \& Cannella, 2001; Arthur et al, 2008). This type of view of young children is not widely endorsed by other sectors, even including the larger education sector, where approaches to learning are often more compartmentalised and structured. As more players enter the game on the ECEC field, the possibility of privileging the holistic, strength-based views of children and childhood which the ECEC sector provides is slowly diminishing. Therefore, it is likely that the space for united activism or advocacy is also eroded.

Notions of fragmentation are exemplified by ECEC's association with education. While this statement might appear to be an anomaly to some, the ECEC sector's relationship to education can ironically constrain rather than enable the practice that early childhood practitioners hold dear. Programs related to formal education tend to be much more structured and more performance based (Macfarlane, 2006; Popkewitz, 2004, 2008). Therefore, as performance-based curriculum underpins systemic practice in education, possibilities for children to be active learners who negotiate their own learning are significantly lessened. Moreover, Lee and McWilliam (2007) argue that the education community's current 'maps to the field' (p. 4) are mono professional and only 'tenuously connected to larger social and economic processes and dated in terms of the landscape of current and emergent social policy' (p.4). These authors initiated such arguments in the article by McWilliam and Lee (2006, p. 48), where they stated that education as a distinctive category

... perpetuates the presumption or belief that education is a domain of knowledge production that can and should be held apart from other knowledge domains in order to do its best work. It is intimately connected to the project of disciplinarisation and paradigmatic self-identity.

Association with an education sector committed to such a mono-disciplinary stance may not benefit the ECEC field, where the holistic welfare of children and families and socio-cultural frameworks are so important. As Moss (2006) attests, such an association makes ECEC practice problematic and does nothing to encourage the interdisciplinarity mandated by integrated practice or to improve the morale or identity of the ECEC workers in child care. Therefore, the ECEC sector at large might highly value its association with education over its association with care, and view its educative importance as integral to its work with children and families. However, ironically, unquestioned adherence to education could eventually erode the value of the ECEC knowledge base and also further lessen opportunities for united activism or advocacy.

\section{The Referees of the Game}

Policy moves towards dichotomous or integrated approaches have also produced changes on the ECEC field that have caused a shift in the positional practice of players in the game. Consequently, notions of dichotomous and integrated practice have worked to highlight the differences between the players, and thus have also worked to change how such players are situated in the game in terms of having the 'right to speak' (Ball, 1990). Thus, in ECEC, the referees in the game - those with this right to speak - have changed. Indeed, what has been signified by these changes in policy direction is that some of the referees in the game both decide the rules and are positioned as players, a fact which highly complicates their position and makes it difficult to determine who decides the rules of the game. This difficulty becomes particularly problematic when a united and cohesive position on ECEC is necessary to inform the direction of government policy to improve the position of children and families in the birth-to-eight-years age group.

An example of this dual position exists in the role of Early Childhood Australia (ECA). Historically, ECA (formally the Australian Early Childhood Association - AECA) has represented the position of early childhood practitioners and has advocated for the rights of young children in Australia. ECA has a strong position nationally and certainly has a sound reputation on the ECEC field, particularly in terms of its advocacy for children. However, ECA largely represents and is supported by early childhood teachers and academics from the discipline of education. Moreover, at the ECA conference held in Brisbane in 2005, the national president, Judy Radich, advocated supported ECA's position that early childhood teachers should staff pre-school rooms in child care centres. This position has been endorsed by the Queensland government and the Australian government and became part of policy direction in 2009 and 2010. 
In Moss's (2006) terms, a move to situate early childhood teachers firmly within the child care arena disrupts current child care discourses. It also attempts to align the pedagogic and child care discourses (Moss, 2006), to try and close the 'widening care-education divide' (Elliott, 2006, p. 14). However, to attempt such a move on this particular field at the moment does not take into account how the various players in the game who sit outside the discipline of education will be impacted.

Such notions are not meant to represent our disagreement about the movement of early childhood teachers into child care - in fact, we both support such a move. Rather, what these perspectives are meant to signify is that attempts to align pedagogic and child care discourses are extremely problematic in the current context, particularly in some states. Such attempts do not take into account the complexity of the arrangements in these states. For example, in Queensland, child care centres are staffed by individuals who hold either advanced diplomas in children's services or degrees in human services, children's services, early childhood education or other social sciences. The core business of the graduates of these programs is often diverse, allowing them to participate in wider disciplinary work. Many of these degrees are three-year programs that do not produce registered teachers. Early childhood education degrees are almost exclusively four-year programs or longer ones, producing registered teachers whose core business is to teach. Thus, there are marked differences between these graduates in terms of their practice, knowledge, skills and perspectives.

\section{A Shrinking Space for Activism?}

What is certain is that now that moves towards integrated practice are more part of the game on the ECEC field in Queensland and in Australia as a whole, practitioners who work in child care have come under further scrutiny. As players on the ECEC field now come from multiple disciplines, such as health, human services, education and social work, child care practitioners are now subject to multiple programs delivered in their centres by many of these professionals, which impact positively and negatively on their practice. Moreover, government intervention in the ECEC sector now comes from new referees, including those in departments of health and community services, ensuring that new rules govern the game that ECEC practitioners and their new counterparts play on this field. While such intervention might be perceived as enriching, given that expertise from education, health and community services is now more available to child care practitioners, ironically this may not be the case. As child care practitioners are generally undertrained and often starved for alternative ways to enact their practice, they can take on board 'new' ways of practising that are offered by professionals from other disciplines as answers to their practice dilemmas. As professionals from more disciplines begin to play the game on the ECEC field, such 'new' ways are more likely to be underpinned by health, child protection and medical models that may be deficit based. Such a process has the effect of further eroding the ECEC knowledge base and its holistic and strengths-based approaches to practice with young children and their families, situating ECEC firmly and only as aligned with more traditional and formal approaches, which are part of the wider education discipline, whilst child care is seen as firmly part of early intervention and prevention practice. This new movement towards inter-professional practice, then, requires a strongly united approach to advocacy by the ECEC sector, in order that the important knowledge contained in the ECEC knowledge base is not lost. However, current fragmentation in the field suggests such advocacy may not be possible.

Moreover, programs that train directors in child care centres but do not produce registered teachers are significantly disadvantaged by moves that seek to erroneously 'add' education to child care. Such a move suggests that education does not presently occur in child care centres, and while concern about the quality of child care is high within the ECEC sector, there would be few in this sector who would argue such a position. To do so would undermine the fabric of the ECEC knowledge base that aligns care, education and development in ways that are not replicated in any other sector or by any other discipline.

As Sumsion (2006) attests, the field faces significant challenges in the coming years, and it is vital that all members of the ECEC sector are supported to achieve critical literacy, critical imagination and critical action. While significant progress is being made in terms of how important the early years of life are seen as being to development across the life course, how important ECEC 
is identified as being, and how necessary well-trained staff are deemed to be, as a sector it is necessary to comprehend the issues that are problematic and the 'truths' that constrain unity so that solutions can be found to the ironies that beset our field in Queensland and across Australia. Thus, the ECEC sector in Queensland and in Australia as a whole must stand united in the game before it can be successful in achieving the quality to which its members aspire.

\section{Conclusions}

This article has sought to highlight some issues for discussion related to achieving cohesive action and advocacy for ECEC in Queensland and, to some extent, in Australia as a whole. We strive to point out that, as ECEC has now become a major focus of government policy, it is more important than ever before for those of us who work in the field to be united and coherent in our advocacy for ECEC as a knowledge base and focus of study. This unity is all the more vital as governments seek to privilege some parts of the sector over others, for the inclusion of some approaches from a fragmented community will always occur at cost of the exclusion of others (Popkewitz, 2008).

We do not suggest that the progress that has been made in Queensland is unwelcome. Indeed, what is occurring in terms of signifying the importance of the early childhood teacher's role in the care and education of 3-4-year-olds has been the culmination of a long-fought battle. However, in Brennan's (2008) terms, the education the 3-4-year-olds is not the 'only game in town' (p. 3). It would be disappointing to think that increased provision for 3-4-year-old children in new 'extended' kindergartens would occur at the 'expense' of increased resources for infants and toddlers or those who are currently working incredibly hard to improve the child care sector as it exists today. Such a notion should surely be unthinkable for ECEC practitioners. The challenge, therefore, is to remain united in our efforts to improve ECEC for all children and families, and ensure that the early childhood knowledge base remains the focus of future government policy direction in this respect.

By using Bourdieuian notions of habitus, game and field and the Foucauldian notion of games of truth and error, the article highlighted some aspects of present policy direction in Queensland as problematic. What has also been highlighted is that each game is constituted in a unique way, and therefore using other ECEC games as examples of ways in which the ECEC sector in Queensland can move forward is problematic at best. ECEC practitioners need to participate in the Queensland game and highlight aspects of its uniqueness in order that practitioners in other states and countries and from other disciplines can see that there are multiple issues at play and that therefore multiple solutions are necessary. Clearly, adherence to only one way of practising is unworkable.

\section{Note}

[1] The authors have chosen the option to use the term 'practitioners' as representative of professionals and practitioners in the ECEC sector, as it is the more encompassing term.

\section{References}

ABC.net.au (2008) http: / /www.abc.net.au/news/stories/2008/08/31/2351027.html

Arthur, L., Beecher, B., Death, E., Dockett, S. \& Farmer, S. (2008) Programming and Planning in Early Childhood Settings, 4th edn. Melbourne: Thomson.

Ball, S.J. (Ed.) (1990) Foucault and Education: disciplines and knowledge. London: Routledge.

Bourdieu, P. (1984) Distinction: a social critique of the judgment of taste. Cambridge, MA: Harvard University Press.

Bourdieu, P. (2001) The Forms of Capital, in M. Granovetter \& R. Swedberg (Eds) The Sociology of Economic Life, 2nd edn, pp. 96-111. Boulder, CO: Westview Press.

Bowe, R. \& Ball, S.J., with Gold, A. (1992) Reforming Education and Changing Schools: case studies in policy sociology. London: Routledge.

Brennan, D. (2008) The Business of Caring.

http: / / www.theage.com.au/opinion/ the-business-of-caring-20081112-5o0d.html (accessed 13

November 2008). 
Burton, J. \& Lyons, M. (2000) When Does an Early Childhood Teacher Teach? in J. Hayden (Ed.) Landscapes in Early Childhood Education: cross national perspectives on empowerment, pp. 271-290. New York: Peter Lang.

David, T., Gooch, K., Powell, S. \& Abbot, L. (2003) Birth to Three Matters: a review of the literature. Research Report 444. London: Department for Education and Skills.

Department of Communities, Disability Services and Seniors (Queensland) (2006) Towards an Early Years Strategy. Brisbane: Queensland Government.

Department of Families, Housing, Communities and Indigenous Affairs (2004a) Stronger Families and Communities Strategy. Canberra: Australian Government.

Department of Families, Housing, Communities and Indigenous Affairs (2004b) National Agenda for Early Childhood, Australian Government.

Department of Families, Housing, Communities and Indigenous Affairs (FaHCSIA) (2009) Family Support Program. Canberra: Australian Government.

Elliott, A. (2006) Early Childhood Education: pathways to quality and equity for all children. Camberwell, VIC: ACER Press.

Farrell, A., Tayler, C. \& Tennent, L. (2004) Building Social Capital in Early Childhood Education and Care: an Australian study, British Educational Research Journal, 30(5), 623-632. http: / / dx.doi.org/10.1080/0141192042000234610

Foucault, M. (1978) Governmentality, in G. Burchell, C. Gordon \& P. Miller (Eds) The Foucault Effect, pp. 87-104. London: Harvester Wheatsheaf.

Foucault, M. (1979) Discipline and Punish. London: Penguin.

Foucault, M. (1980) Truth and Power, in C. Gordon (Ed.) Power/Knowledge: selected interviews and other writings, 1972-77, pp. 109-133. New York: Pantheon.

Foucault, M. (1984) The Ethics of the Concern of the Self as a Practice of Freedom, in P. Rabinow (Ed.) Michel Foucault, Ethics: essential works of Foucault 1954-1984, vol. 1, pp. 281-301. London: Penguin.

Foucault, M. (1985) The History of Sexuality. Vol 2: The Use of Pleasure. New York: Pantheon.

Foucault, M. (1991) The Politics and the Study of Discourse, in G. Burchell, C. Gordon \& P. Miller (Eds) The Foucault Effect, pp. 53-72. London: Wheatsheaf.

Grieshaber, S. \& Cannella, G. (2001) Embracing Identities in Early Childhood Education: diversity and possibilities. New York: Teachers College Press.

Hutchins, T. \& Sims, M. (1999) Program Planning for Infants and Toddlers: an ecological approach. Sydney: Prentice Hall.

Lee, A. \& McWilliam, E. (2007) What Game are We In? Living with Academic Development, International Journal for Academic Development, 13(1), 67-77. http: / / dx.doi.org/10.1080/13601440701860284

Macfarlane, K. (2006) An Analysis of Parental Engagement in Contemporary Queensland Schooling. PhD thesis, Queensland University of Technology.

Macfarlane, K. \& Cartmel, J. (2007) Report to the Community Services and Health Workforce Council (Queensland) on the Circles of Change (Revisited) Project. Brisbane: Griffith University.

Macfarlane, K. \& Cartmel, J. (2008) Playgrounds of Learning: valuing competence and agency in birth to three year olds, Australian Journal of Early Childhood, 33(7), 41-48.

Macfarlane, K. \& Lewis, P. (2004) Child Care - Human Services or Education: a genealogical approach, Contemporary Issues in Early Childhood, 5(1), 51-67. http: / / dx.doi.org/10.2304/ ciec.2004.5.1.9

McWilliam, E. \& Lee, A. (2006) The Problem of the Problem with Educational Research, Australian Educational Researcher, 33(2), 43-60. http: / / dx.doi.org/10.1007/BF03216833

Moss, P. (2002) Time to Say Farewell to Early Childhood, Contemporary Issues in Early Childhood, 3(3), 435-438. http:// dx.doi.org/10.2304/ ciec.2002.3.3.9

Moss, P. (2006) Farewell to Childcare, National Institute Economic Review, 195(1), 70-83.

Moss, P. \& Pence, A. (1994) Valuing Quality in Early Childhood Services. London: Paul Chapman.

Moss, P. \& Petrie, P. (2002) From Children's Services to Children's Spaces: public provision, children and childhood. London: RoutledgeFalmer.

Petrie, A. (1988) Education and Care: the false dichotomy, Australian Journal of Early Childhood, 13(36), 26-30.

Popkewtiz, T. (2004) The Reason of Reason: cosmopolitanism and the governing of schooling, in B. Baker $\&$ K. Heyning (Eds) Dangerous Coagulations, pp. 181-212. New York: Peter Lang. 
Popkewitz, T. (2008) Cosmopolitanism and the Age of School Reform: science, education and making society by making the child. New York: Routledge.

Queensland Government (2008) Toward Queensland 2: Tomorrow’s Queensland. Brisbane: Queensland Government.

Radich, J. (2005) Keynote address, Early Childhood Australia Conference, Kaleidoscope: changing images of childhood, 28 September-1 October, Brisbane.

Rose, N. (2000) Community, Citizenship and the Third Way, American Behavioural Scientist, 43(9), 1395-1411. http: / / dx.doi.org/10.1177/00027640021955955

Sumsion, J. (2006) From Whitlam to Economic Rationalism and Beyond: a conceptual framework for political activism in children's services, Australian Journal of Early Childhood, 31(1), 1-8.

SureStart (2008) http: / www/SureStart.com

KYM MACFARLANE is the convenor of the child and family studies program in the School of Human Services and Social Work at Griffith University. Her research interests include poststructuralist theory, social inclusion, early childhood education and care, and transdisciplinary practice.Correspondence: k.macfarlane@griffith.edu.au

PATRICIA LEWIS is currently undertaking a Certificate in Anthropology at the University of Oxford in the UK. 